Available online at GSC Online Press Directory

GSC Biological and Pharmaceutical Sciences

e-ISSN: 2581-3250, CODEN (USA): GBPSC2

Journal homepage: https://www.gsconlinepress.com/journals/gscbps

(RESEARCH ARTICLE)

\title{
Development of the gastrointestinal tract microflora in young carrier pigeons
}

\author{
František Zigo ${ }^{1,}{ }^{*}$, Anna Tarčáková ${ }^{1}$ and Silvia Ondrašovičová ${ }^{2}$ \\ ${ }^{1}$ Department of Nutrition and Animal Husbandry, University of Veterinary Medicine and Pharmacy, Košice, Slovakia \\ ${ }^{2}$ Department of Biology and Physiology, University of Veterinary Medicine and Pharmacy, Košice, Slovakia.
}

Publication history: Received on 15 November 2020; revised on 23 November 2020; accepted on 25 November 2020

Article DOI: https://doi.org/10.30574/gscbps.2020.13.2.0383

\begin{abstract}
The high demands placed on the performance of carrier pigeons are often reflected in their health and reduced immunity. Therefore, it is important to take sufficient care of their health from the hatching throughout the rearing of future competitors. The aim of the study was to monitor the development of the bacterial microbiota of the gastrointestinal tract (GIT) during the first month of their life. Two examinations of young pigeons involved taking of swabs from crop and cloaca at $5^{\text {th }}$ day after hatching and $30^{\text {th }}$ day of weaning, when exposure of young pigeons to stress was expected. The results of the study suggested that crop microbiota of young pigeons until weaning is dominated by lactobacilli, such as L. fermentum, L. mucosae or L. agilis, and host-specific bacteria, namely enterococci and streptococci. From the cloacal swabs, E. coli, Ent. faecalis and Str. faecalis were most frequently detected during the two samplings. Commensal bacteria, particularly Str. gallolyticus and Str. sanguinis, which are part of the gastrointestinal microbiota, can act as opportunistic pathogens, mainly under stress conditions resulting in susceptibility to various diseases.
\end{abstract}

Keywords: Carrier Pigeons; Hatching; Swabs; Crop; Cloaca; Lactobacilli.

\section{Introduction}

Today, high demands are placed on the performance and health of carrier pigeons. Neat appearance and the ability to give top performance are the two most important traits that breeders try to achieve [1,2].

If a breeder wants to succeed with his pigeons at races and shows, he must give them adequate care starting from hatching. Only a healthy pigeon can give maximum performance according to its abilities and present oneself to good advantage at shows attended by the breeding public. The predator can easily catch a sick pigeon and the indisposed, huddled bird pigeon will not impress the judges at any show and will be eliminated from the judging [3].

The breeders make an effort to ensure the best possible health of young carrier pigeons by developing and implementing suitable prophylactic programs and providing the birds balanced feed rations and a wide range of nutritional supplements. Every breeder should realize that the various stress factors to which an individual is exposed during its life weaken the organism and make it more susceptible to diseases [4].

Weaning and separation of young pigeons from their parents, training and the races themselves belong among the most serious stressors that affect their health and composition of the bacterial microbiota of their digestive tract [5]. For this reason, this study was aimed at monitoring of the development and changes in bacterial microbiota in the gastrointestinal tract (GIT) of young carrier pigeons during the first month of their life.

\footnotetext{
* Corresponding author: František Zigo

Department of Nutrition and Animal Husbandry, University of Veterinary Medicine and Pharmacy, Košice, Slovaki. 


\section{Material and methods}

\subsection{Holding and breeding season}

The practical part of the study was performed in a pigeon loft for carrier pigeons of dimensions $4 \times 2 \mathrm{~m}$ located in eastern Slovakia. The inner part of the structure comprised wooden perches and nesting boxes of size $60 \times 40 \mathrm{~cm}$. Next to the loft there was an aviary that was made of mesh. Depending on the climatic conditions, pigeon nesting starts in the second half of February and lasts to the first half of March. After laying, the eggs are regularly inspected. The surface is examined visually for its quality, signs of damage and contamination of the shell. The egg content is also checked by candling in order to observe the signs of fertilization.

After 17 - 19 days of incubation, blind pigeons are hatched covered only by fine yellow down. During the first 10 days, the young are carefully cared for by their parents. They feed their offspring yellow slurry produced in their crop, the socalled crop milk (Figure 1). The consistency of the crop milk changes over time until contains whole softened grains. By three weeks of age the young are grown up, leave the nest and start to consume the feed themselves, but still require additional feeding by their parents. In the fourth week after hatching, the young are separated from their parents and transferred to separate section equipped with a perches, feeder and drinker.

\subsection{Sampling and laboratory analysis}

During the study, two samples were taken from each of 30 young pigeons. Sampling was performed in relation to exposure of birds to stressful situations, always when a certain level of stress was expected, accompanied with change in microbiota and its effect on the overall health of individual birds. The first collection was performed on day 5 after hatching in an effort to record the highest lactobacilli counts (Figure 2). The second collection was carried out one month after hatching, when the young were separated from their parents and transferred to a separate section.

Each sample was cultivated on conventional nonselective media (blood agar) and selective media (Endo agar) under aerobic conditions according to Facklam and Collins [6] and Kimpe et al. [7]. Fermentative gram-negative rods of the family Enterobacteriaceae were determined by standard biochemical procedures using Enterotest 24 (Lachema, Czech Republic). Streptococci were identified according to their characteristics growth on blood agar (Oxoid) and by standard biochemical procedures using Streptotest 24 (Lachema). To examine samples for the presence of lactobacilli were swabs cultured in MRS agar at $37^{\circ} \mathrm{C}$ for 24 hours and inoculated into the medium MRS supplemented with $0.05 \%$ by volume of cysteine hydrochloride (BTL, Poland).
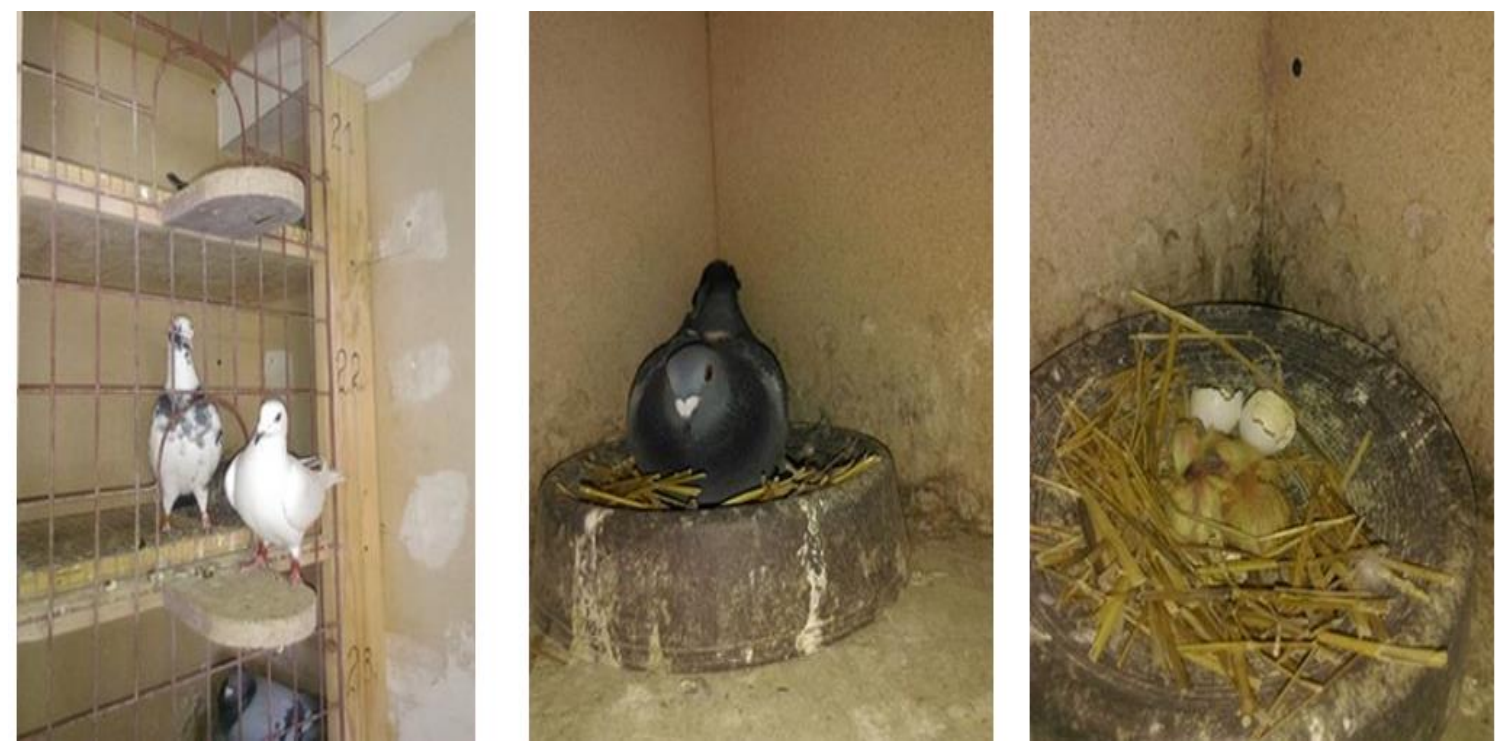

Figure 1 Mating, nesting and hatching of pigeons Source: Foto by Tarčákova (2018) 

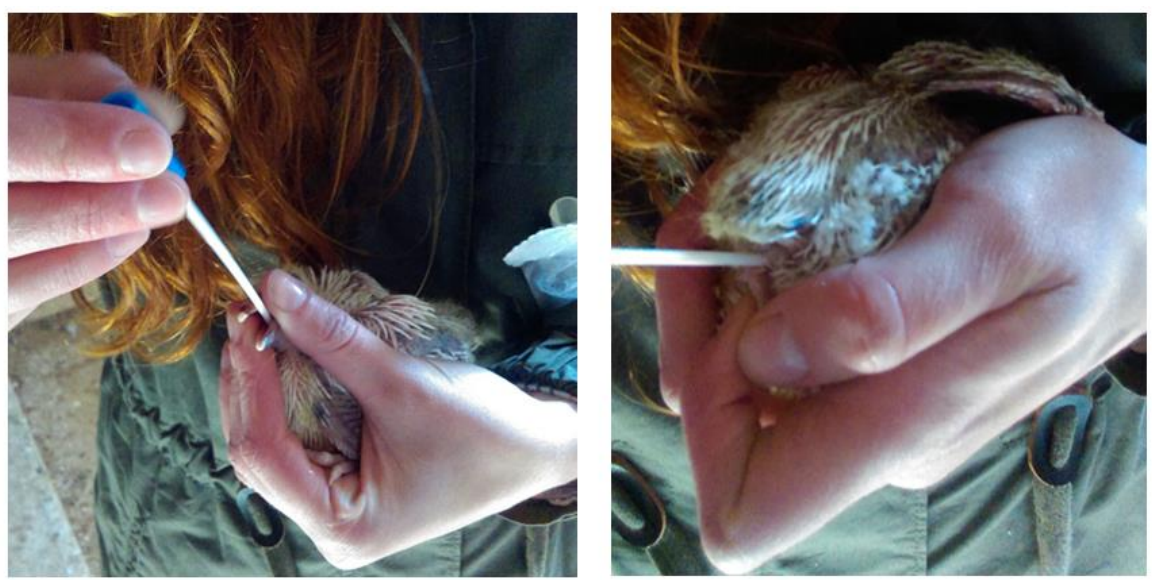

Figure 2 Sampling swabs of the crop and cloaca Source: Foto by Tarčákova (2018)

To examine the swabs for the presence of lactobacilli, they were cultured on MRS agar at $37{ }^{\circ} \mathrm{C}$ for 24 hours and inoculated into MRS medium MRS supplemented with $0.05 \%$ (by volume) of cysteine hydrochloride (BTL, Poland). The plates were incubated at $37{ }^{\circ} \mathrm{C}$ for an additional 48 hours in $5 \% \mathrm{CO}_{2}$ atmosphere. Of the typical colonies grown on MRS medium only catalase negative, Gram-positive rods were considered to belong to the genus Lactobacillus. Utilization of saccharide was tested by means of an API assay (API 50 CHL, BioMérieux, France) and the results were analysed using APILAB Plus software (Ver.3.3.3, BioMérieux, France).

\subsection{Statistical analysis}

Statistical processing and evaluation of the results were performed in Microsoft Excel and IBM SPSS v. 20. The significance of the differences in the mean values between the samplings was tested by t-test at a significance level of 0.05 .

\section{Results and discussion}

Examination of 30 young carrier pigeons during the first month after hatching detected 10 different species of bacteria from crop and cloacal swabs with the highest abundance of Escherichia coli. This species was found in almost $90 \%$ of cloacal swabs taken from the examined birds. Streptococcus gallolyticus was the most common bacterium detected in crop where it occurred in more than $70 \%$ of birds at first sampling. Enterococus columbae and Ent. faecalis were found in one third of the examined young pigeons (Table 1).

Table 1 Development of bacterial microflora in young pigeons $(n=30)$

\begin{tabular}{|c|c|c|c|c|c|c|c|c|}
\hline \multirow{3}{*}{ Isolated bacteria } & \multicolumn{4}{|c|}{ I. Sampling } & \multicolumn{4}{|c|}{ II. Sampling } \\
\hline & \multicolumn{2}{|c|}{ Cloaca } & \multicolumn{2}{|c|}{ Crop } & \multicolumn{2}{|c|}{ Cloaca } & \multicolumn{2}{|c|}{ Crop } \\
\hline & $\mathrm{n}$ & $\%$ & $\mathrm{n}$ & $\%$ & $\mathrm{n}$ & $\%$ & $\mathrm{n}$ & $\%$ \\
\hline E. coli & 27 & 89.0 & 13 & 42.0 & 29 & 96.6 & 17 & 56.1 \\
\hline Str. gallolyticus & 4 & 1.2 & 22 & 72.6 & - & - & 5 & 16.5 \\
\hline Ent. faecalis & 7 & 23.0 & 3 & 10.0 & 17 & 56.1 & 5 & 16.5 \\
\hline Ent. columbae & 3 & 10.0 & 5 & 16.5 & - & - & 8 & 26.4 \\
\hline L. fermentum & 5 & 16.5 & 11 & 36.3 & - & - & 4 & 13.2 \\
\hline L. mucosae & - & - & 4 & 13.2 & - & - & - & - \\
\hline L. agilis & - & - & 6 & 19.8 & - & - & 3 & 10.0 \\
\hline Lactobacillus spp. & 2 & 6.6 & 5 & 16.5 & 3 & 10.0 & 2 & 6.6 \\
\hline Citrobacter spp. & 3 & 10.0 & - & - & 4 & 13.2 & - & - \\
\hline Str. sanguinis & - & - & - & - & - & - & 8 & 26.4 \\
\hline
\end{tabular}

Note: $\mathrm{n}$ - number of positive pigeons; I. Sampling - crop and cloacal swabs at $5^{\text {th }}$ day after hatching; II. Sampling - crop and cloacal swabs at $30^{\text {th }}$ day of weaning. 
The presence of E. columbae and S. gallolyticus in the pigeon GIT was to be expected. According to Devriese et al. [8,9] the former species has been described from pigeons and it has been found to date only in this animal host.

The incidence of diseases in young pigeons during their growth may affect the presence of bacterial microflora. Microbial flora of the pigeon gastrointestinal tract is characterized by occurrence of enterococci and E. coli. Escherichia coli is usually commensal, but can also act as an opportune pathogen. Several factors are needed for $E$. coli to cause disease in pigeons, such as stress or adenoviral or herpesviral infection [10].

Also, Baele [11] confirmed that the dominant species of the GIT microbiota of pigeons are enterococci and streptococci. The most abundant enterococci detected in the GIT of pigeons included Enterococcus columbae and to a lesser extent Enterococcus cecorum. Other, less common enterococci were E. faecalis, E. faecium, E. gallinarum and E. casseliflavus. Streptococcus gallolyticus and Str. faecalis were also part of the intestinal microbiota of these birds.

Hand [1] reported that grain-eating birds have the highest proportion of Lactobacillus spp., Enterococcus spp. and various Clostridiaceae in GIT. Lactobacilli were the dominant genus, particularly in young individuals, which was confirmed also by our study. Of the lactobacilli, mainly L. fermentum with $36.3 \%$, L. mucosa with $13.2 \%$ and L. agilis with a prevalence of $19.8 \%$ were found in the crop (Table 1 ).

The results of the first sampling conducted on day 3 after hatching reflected gradual colonisation of the GIT of young pigeons by bacterial microbiota. We detected the highest abundance of bacteria of the genus Lactobacillus that form a protective film on the surface of GIT mucosa and are needed for the digestion of crop milk.

According to Johansson et al. [12] and the isolated strains L. agilis and L. mucosae from pigeon crop possess specific attachment mechanisms to crop epithelium, as has been documented amply in the case of the chicken crop. Gradually, as the density of secretion from the crop of parents feeding the young increased with increasing proportion of whole grains, the proportion of lactobacilli decreased as was reflected in the swabs taken during the second sampling. By analysis of samples collected at the time of separation of the young from their parents we wanted to point to the changes associated with the first stressful moment in the lives of young pigeons. During the period between the two samplings, there was a significant change in the bacterial microbiota of their GIT. We detected a significant decrease in lactobacilli and an increase in enterococci (Figure 3 and 4).

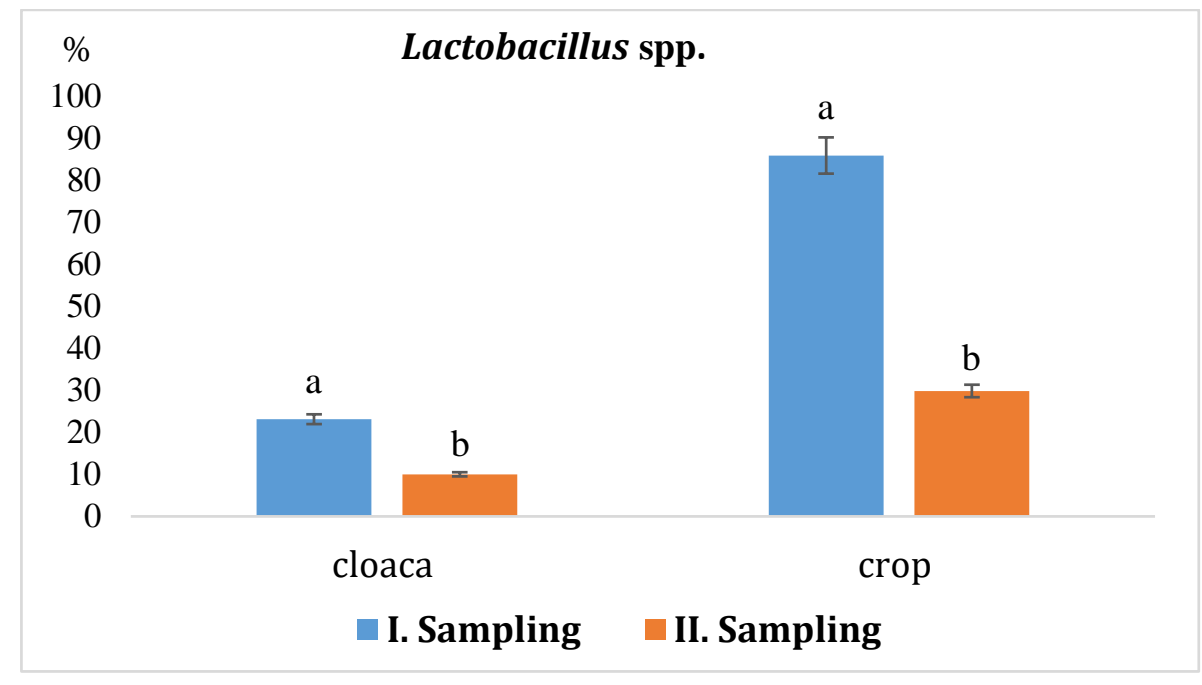

Figure 3 Comparison of the development of Lactobacillus spp. in young pigeons

Note: I. sampling - crop and cloacal swabs at $5^{\text {th }}$ day after hatching; II. Sampling - crop and cloacal swabs at $30^{\text {th }}$ day of weaning. a,b - values above the columns sharing different letters are significantly different $(P<0.05)$ 


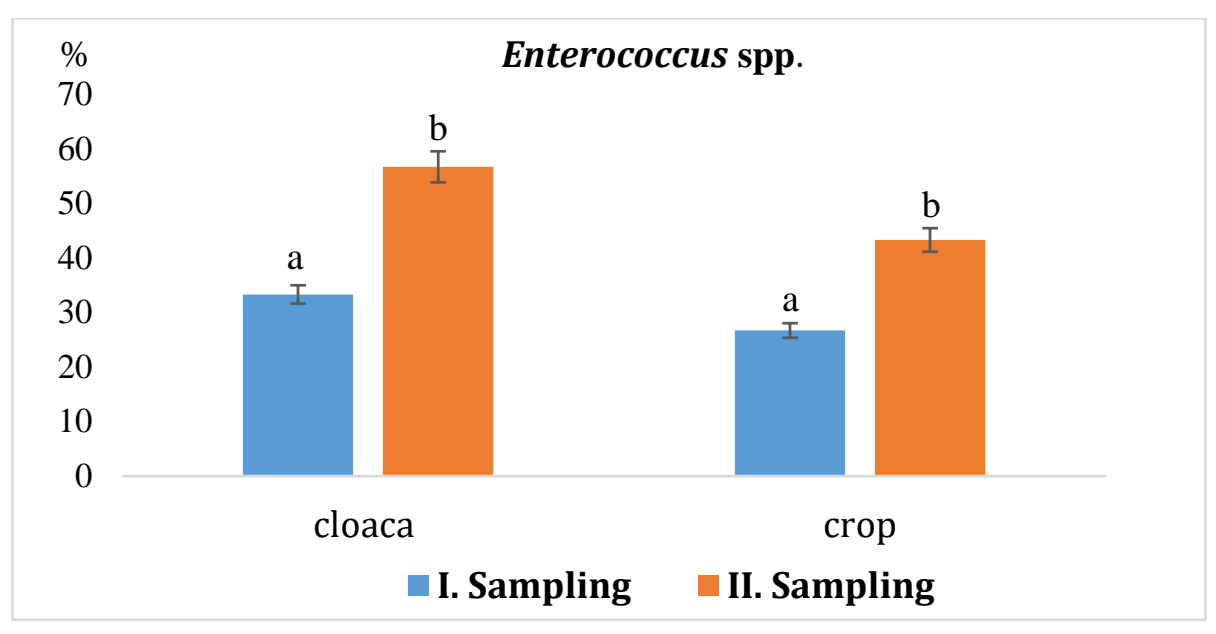

Figure 4 Comparison of the development of Enterococcus spp. in young pigeons

Note: I. Sampling - crop and cloacal swabs at $5^{\text {th }}$ day after hatching; II. Sampling - crop and cloacal swabs at $30^{\text {th }}$ day of weaning. a,b - values above the columns sharing different letters are significantly different $(P<0.05)$

Xu et al. [14] showed that probiotics have a variety of biological functions and beneficial effect in the poultry industry. They can produce molecules with antimicrobial activity, target specific pathogens, and even inhibit the adhesion of pathogens. They can also improve intestinal morphology, maintain intestinal microbial balance, and interact with host to improve immunity.

\section{Conclusion}

Results of our study showed that the microbiota of young pigeons during the first 5 days after hatching is dominated mainly by host-specific bacteria such as lactobacilli and enterococci. During the growth of pigeons, their abundance changes which was evident at second sampling one month after hatching. After weaning, enterococci, E. coli and streptococci in particular were dominant in the swabs. Commensal bacteria, such as E. coli, Str. gallolyticus and Str. sanguinis, which are part of the GIT microbiota, can also act as opportunistic pathogens, mainly due to many stressful conditions that lead to significant exhaustion of birds and their increased susceptibility to various diseases.

\section{Compliance with ethical standards}

\section{Acknowledgments}

This work was supported by the Slovak project KEGA no. 006UVLF-4-2020 'Implementation of new scientific knowledge in teaching and improving the practical training of students in breeding technology from subject Animal husbandry'.

\section{Disclosure of conflict of interest}

The authors declare that there is no conflict of interest in the present study.

\section{References}

[1] Hand 0. The Effects of Stress on Racing Pigeons. [Internet], 2004; [cited 2019 Aug 10]. Available: http://www.pigeonbasics.com/articles/article79.html.

[2] Zigo F, Takáč L, Chripková M, Tomko M, Takáčová J, Toropilová D. Infectious diseases of carrier pigeons and antimicrobial resistance in isolated bacteria. Int J of Sci Res. 2016; 5: 2277-8179.

[3] Struhár, M. Holuby a ich zdravie/Pigeons and their health (In Slovak). Zohor, 2015; ISBN 978-80-89783-02-1, p. 74.

[4] Zigo F, Ondrašovičová S, Zigová M, et al. Influence of the flight season on the health status of the carrier pigeons. Int J Avian \& Wildlife Biol. 2019; 4(2):26-30. 
[5] Scullion FT, Scullion MG. Investigation of diseases in young racing pigeons. [Internet], 1997; [cited 2019 Aug 10] Available: http://www.wmenews.com/Information/Other/Section4Scullionetalpp73-75pdf.pdf.

[6] Facklam RR, Collins MD. Identification of Enterococcus species isolated from human infections by conventional test scheme. J. Clin. Microbiol. 1989; 27:731-734.

[7] Kimpe A, Decostere A, Martel A, Haesebrouck F, Devriese LA. Prevalence of antimicrobial resistance among pigeon isolates of Streptococcus gallolyticus, Escherichia coli and Salmonella enterica serotype Typhimurium. Avian Pathol. 2002; 31:393-397.

[8] Devriese LA, Ceyssens K, Rodrigues UM, Collins MD). Enterococcus columbae, a species from pigeon intestines. FEMS Microbiology Letters. 1990; 59:247-251.

[9] Devriese LA, Vandamme P, Pot B, Vanrobaeys M, et al. Differentiation between Streptococcus gallolyticus strains of human clinical and veterinary origins and Streptococcus bovis strains from the intestinal tracts of ruminants. Journal of Clinical Microbiology, 1998; 36:3520-3523.

[10] Rupiper DJ, Ehrenberg M. Practical pigeon medicine. Proc Assoc Avian Vet.1997:479-497.

[11] Baele M, Devriese LA, Butaye P, et al. Composition of enterococcal and streptococcal flora from pigeon intestines. Jour of Appl Mic. 2002; 92:348-351.

[12] Johansson ML, Molin G, Jeppsson B, Nobaek S, Ahrne S, Bengmark S. Administration of different Lactobacillus strains in fermented oatmeal soups in vivo colonization of human intestinal mucosa and effect on the indigenous floora. Applied and Environmental Microbiology. 1993; 59:15-20.

[13] Prescott JF, Smyth JA, Shojadoost B, Vince A. Experimental reproduction of necrotic enteritis in chickens: a review. Avian Pathol. 2016; 45:317-22.

[14] Xu T, Chen Y, Yu L. et al. Effects of Lactobacillus plantarum on intestinal integrity and immune responses of egglaying chickens infected with Clostridium perfringens under the free-range or the specific pathogen free environment. BMC Vet Res. 2020; 16(1):47. 